\title{
Simulasi CFD Dinamika Kecepatan Gelombang Aliran Stratified Wavy Dua Fasa Minyak-Air pada Pipa Horizontal
}

\author{
P.P. Jati* dan A.Widyaparaga \\ Departemen Teknik Mesin dan Industri, Fakultas Teknik, Universitas Gadjah Mada. \\ Jl. Grafika No.2, Kompleks UGM, Yogyakarta 55281, Indonesia, \\ Telp. (0274) 521673 \\ e-mail: pandu.prabowo.j@mail.ugm.ac.id
}

\begin{abstract}
Abstrak
Dalam praktik di industri hulu minyak dan gas (migas), permasalahan aliran dua fasa merupakan bagian penting di semua siklus kegiatan dari desain hingga operasi. Fluida dari sumur produksi menghasilkan campuran minyak, air, gas, dan juga pasir yang sangat mungkin membentuk berbagai macam pola aliran. Sehingga dapat disimpulkan bahwa pemahaman akan pola aliran dan sifat fluida sangat penting untuk analisis, prediksi, dan mitigasi perubahan kondisi reservoir untuk menjaga stabilitas proses produksi. Untuk meningkatkan pemahaman pola aliran salah satunya pola stratified dilakukan penelitian mencari konfigurasi simulasi 2 dimensi campuran minyak dan air menggunakan Computational Fluid Dynamics (CFD). Penelitan yang dilakukan menghasilkan analisis sifat dinamika kecepatan gelombang melalui perpaduan permodelan simulasi CFD serta image processing-cross correlation serta perbandingan hasil dengan eksperimen. Model yang dipilih untuk memprediksi antarmuka minyak-air di dalam pipa horizontal berdiameter $24 \mathrm{~mm}$ dan panjang $1200 \mathrm{~mm}$ adalah multiphase Eulerian Multi-Fluid VOF yang dipasangkan dengan model turbulensi shear stress transport (SST) k- $\omega$ yang dilengkapi dengan turbulence damping. Analisis dilakukan pada titik dari inlet dengan jarak $10 \mathrm{x}$ diameter (10 D) dan $40 \mathrm{x}$ diameter $(40 \mathrm{D})$ dengan 4 variasi kecepatan. Hasil menunjukkan peningkatan rerata ketebalan film dan kecepatan gelombang seiring dengan meningkatnya kecepatan superfisial air dengan kecepatan superfisial minyak tetap. Dapat disimpulkan model multiphase Eulerian MultiFluid VOF yang dipasangkan dengan model turbulensi shear stress transport (SST) k- $\omega$ dan turbulence damping pada Ansys Fluent 19 mampu mensimulasikan aliran minyak dan air pada stratified regime dengan bentuk gelombang serta dinamika kecepatan gelombang yang saling bersesuaian dengan hasil eksperimen.
\end{abstract}

Kata kunci : computational fluid dynamics (CFD), eulerian multi-fluid VOF, image processing-cross correlation, startified wavy, kecepatan gelombang.

\begin{abstract}
In the upstream oil and gas (oil and gas) industry, the problem of two-phase flow is an important part in all the activity cycles from design to operation. Fluid from the production well produces a mixture of oil, water, gas, and sand resulting in various probability of flow pattern. It can be concluded that understanding of flow patterns and fluid characteristics is very important for the analysis, prediction and mitigation of reservoir changes in order to maintain stable production process. Regarding to improve the understanding of flow patterns, especially stratified flow patterns of oil and water, a 2-dimensional simulation study was carried out using computational
\end{abstract}


fluid dynamics (CFD). The research delivers analysis of the wave velocity dynamics characteristics through CFD modelling and image processing-cross correlation with experiments result comparison. Simulation use the Eulerian Multi-Fluid VOF multiphase model coupled shear stress transport (SST) $k-\omega$ by activating turbulence to predict oil-water interfaces inside horizontal pipes with $24 \mathrm{~mm}$ diameter-length $1200 \mathrm{~mm}$. Analysis carried out at location from the inlet using distance value of $10 \mathrm{x}$ diameter $(10 \mathrm{D})$ and $40 \mathrm{x}$ diameter $(40 \mathrm{D})$ with 4 velocity variation. The result shows increasing average film thickness and the wave velocity when the superficial velocity of the water rises at constant oil superficial velocity. It can be concluded that the Eulerian Multi-Fluid VOF multiphase model coupled with turbulence model shear stress transport (SST) $k-\omega$ by activating turbulence damping on Ansys Fluent 19 is able to simulate the oil and water mixture in a stratified regime where wave formation and its velocity dynamics are aligned with experiment result.

Keywords : computational fluid dynamics (CFD), eulerian multi-fluid VOF, image processingcross correlation, startified wavy, wave velocity.

\section{PENDAHULUAN}

Dalam praktik di industri hulu minyak dan gas (migas), permasalahan aliran dua fasa merupakan bagian penting di semua siklus kegiatan dari desain hingga operasi. Permasalahan aliran dua fasa yang ada menjadikan pemahaman dan analisa tentang pola aliran dan sifat fluida sangat penting. Sehingga, aplikasi praktis terkait pola aliran fluida menjadi sangat penting untuk terus dipelajari khususnya oleh engineer yang bertanggung jawab memberikan rekomendasi keputusan teknis agar kondisi lapangan tetap aman. Pada asset-asset field yang sudah mature, akan banyak ditemui kasus oversize dimana sistem fasilitas memiliki kapasitas desain yang jauh lebih besar daripada fluida yang diolah. Karena berkurangnya laju aliran fluida, maka pola aliran di dalam pipa cenderung menjadi stratified. Oleh sebab itu, peneliti memiliki motivasi untuk mempelajari lebih lanjut fenomena stratified flow yang terkait dengan permasalahan di lapangan yang sudah mature. Selain itu, peneliti berharap untuk meningkatkan pemahaman model matematis melalui pemanfaatan aplikasi CFD (Computational Fluid Dynamics) di dalam penelitan.

Rumusan masalah pada penelitian ini adalah bagaimana membuat konfigurasi simulasi minyak-air pada rezim stratified wavy pada pipa horizontal dengan inlet berbentuk "T" menggunakan Ansys Fluent 19 ${ }^{\text {TM }}$ untuk memperoleh dinamika kecepatan gelombang. Keuntungan melalui pemanfaatan CFD, model yang dibuat dapat dipakai untuk mendapatkan prediksi bentuk gelombang aliran minyak-air serta kecenderungan kecepatan gelombangnya pada rentang variasi kecepatan yang lebih luas tanpa melakukan eksperimen terlebih dahulu.

Melalui penelitian Hanafizadeh (2015) dijelaskan bentuk aliran pada pipa horizontal dengan menggunakan pipa yang memiliki diameter dalam $20 \mathrm{~mm}$. Dari eksperimen dihasilkan berbagai macam pola aliran di antaranya adalah bubbly, slug, smooth stratified, wavy stratified, churn, annular, serta dual continuous. Penelitian yang spesifik terkait pola aliran stratifed dilakukan oleh Barral (2015), yang berpendapat bahwa ketidakstabilan pada antarmuka gelombang di kondisi tertentu, akan menyebabkan naiknya amplitudo gelombang. Gelombang kemudian melepaskan droplet berupa emulsi dari antarmuka gelombang. Munculnya droplet adalah awal mula transisi dari pola aliran stratified ke pola lain.

Berdasarkan penelitian eksperimen menggunakan image processing yang dilakukan oleh Bhaskara (2018) menunjukkan bahwa perubahan kecepatan superfisial tiap komponen campuran fluida minyak-air berbanding lurus dengan kecepatan gelombang yang terbentuk. Dan 
kecepatan gelombang semakin berkurang seiring semakin jauhnya jarak terhadap inlet fluida. Selain itu, penelitian eksperimen juga dilakukan oleh Hanif (2018) menggunakan image processing image yang menunjukkan frekuensi aliran cenderung turun jika menjauh dari inlet fluida dan cenderung naik ketika kecepatan superfisial air maupun minyak meningkat. Dari penelitan penggunaan image processing oleh Bhaskara (2018) serta Hanif (2018) menginspirasi penelitian ini untuk mengaplikasikan image processing dari video simulasi yang diperoleh.

Studi yang sudah dilakukan menjadi menarik untuk diteliti lebih lanjut karena sejauh ini, simulasi yang sudah dilakukan relatif lebih dominan aliran gas-cair. Di sisi yang lain, studi caircair relatif lebih banyak dilakukan dalam metode eksperimental. Kemudian simulasi yang menggunakan model Eulerian MultiFluid VOF relatif belum banyak. Mohammad Akhlaghi di (2019) berhasil mensimulasikan gas-cair menggunakan model Eulerian MultiFluid VOF yang memprediksi penurunan tekanan dengan tingkat kesalahan (error) sebesar 13.1\%. Selain itu, untuk memahami model turbulensi, penelitian menggunakan referensi studi computational fluid dynamics (CFD) aliran dua fasa oleh Shi (2018). Penelitiannya mengaplikasikan model volume of

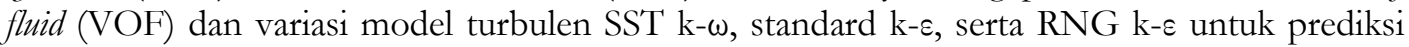
pola aliran dengan gambaran cross-sectional untuk masing masing model turbulensi. Selain itu studi CFD sebagai referensi dilakukan oleh Deendarlianto (2016) terkait plug flow untuk gas-cair pada pipa horizontal, menginsipirasi penelitian ini untuk mengevaluasi hasil simulasi dengan perbandingan visual. Model simulasi yang dipakai oleh Deendarlianto (2016) adalah Volume of Fluid (VoF) menggunakan FLUENT. Pengamatan menggunakan high-speed video menunjukkan kesesuaian kualitatif yang baik dengan eksperimen. Hasil penelitian juga menunjukkan kesesuaian kuantitatif antara perhitungan dan data eksperimen untuk panjang gelembung serta variasi waktu dari liquid hold up.

Dari referensi diatas, penelitian yang dilakukan diharapkan dapat mengetahui kombinasi Eulerian MultiFluid VOF serta model turbulensinya yang optimum untuk simulasi minyak dan air. Di mana penelitian mengaplikasikan image processing untuk evaluasi video hasil simulasi gelombang yang terbentuk dan dinamika kecepatan gelombang.

\section{METODE PENELITIAN}

Penelitian ini mengguanakan desain geometri pipa inner diameter $24 \mathrm{~mm}$ dengan panjang 6 m menggunakan software DesignModeler (DM) dalam ANSYS 19. Pada penelitian ini digunakan 2 titik referensi pengamatan kecepatan gelombang pada jarak $10 \mathrm{D}(10 \mathrm{x}$ diameter $)$ dan $40 \mathrm{D}$ (40 $\mathrm{x}$ diameter) yang juga merupakan titik pengamatan dalam eksperimen. Pengamatan dilakukan dilakukan setelah aliran fully developed dengan cara analisa dimulai setelah menunggu aliran selesai sampai ujung pipa, sehingga pipa sudah terbentuk aliran minyak di bagian atas dan air di bagian bawah. Konfigurasi kepadatan mesh yang dipilih adalah ketika hasil solusi simulasi tidak berubah signifikan saat mesh diperhalus. Adapun gambaran lengkapnya ditunjukkan pada Gambar 1.

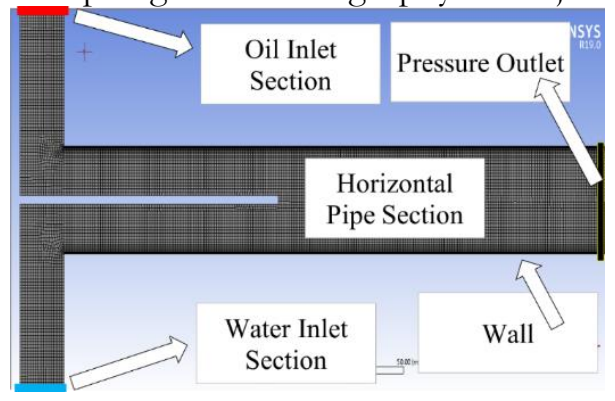


Gambar 1. Konfigurasi bagian mesh (oil inlet, water inlet, pressure outlet, wall)

\subsection{Kondisi Batas (Boundary Conditions)}

Penelitian fokus untuk mempelajari perilaku antarmuka minyak dan air melalui analisis tebal film dan dinamika kecepatan gelombang dalam kondisi transien setelah aliran sudah terbentuk sempurna. Detail konfigurasi ditunjukkan pada Gambar 1. Nilai sifat minyak tanah dan air yang digunakan pada simulasi ini sama dengan nilai pada eksperimen oleh Hanif (2018), yang ditunjukkan Tabel 1.

Tabel 1. Sifat fluida yang Dipakai pada Simulasi pada $\mathrm{T}=300^{\circ} \mathrm{C}$ dan Tekanan $=1 \mathrm{~atm}$

\begin{tabular}{|c|c|c|}
\hline Fluida & Massa Jenis (@) & Viskositas Dinamis $(\boldsymbol{\mu})$ \\
\hline Air & $997 \mathrm{~kg} / \mathrm{m} 3$ & $0,00086 \mathrm{~kg} / \mathrm{m} . \mathrm{s}$ \\
\hline Minyak Tanah & $820 \mathrm{~kg} / \mathrm{m} 3$ & $0,1344 \mathrm{~s}$ \\
\hline
\end{tabular}

Kondisi batas dibagi menjadi 4 bagian utama. Bagian pertama adalah oil inlet section lokasi aliran minyak untuk masuk menuju pipa horizontal, bagian kedua adalah lokasi untuk air masuk atau disebut water inlet. Bagian ketiga yang terletak paling ujung merupakan lokasi tempat fluida baik minyak dan air keluar bersama-sama (yang di set up pressure outlet). Sedangkan yang keempat adalah dinding pipa yang menggunakan wall function. Adapun variasi kecepatan disajikan pada Tabel 2.

Tabel 2. Variasi Kecepatan pada Simulasi.

\begin{tabular}{|c|c|c|}
\hline Variasi & $\begin{array}{c}\text { Kecepatan superfisial minyak } \\
\text { (Vo) }\end{array}$ & $\begin{array}{c}\text { Kecepatan superfisial air } \\
\text { (Vw) }\end{array}$ \\
\hline 1 & $0,221 \mathrm{~m} / \mathrm{s}(6$ liter $/$ menit) & $0,147 \mathrm{~m} / \mathrm{s}$ (4 liter $/$ menit) \\
\hline 2 & $0,221 \mathrm{~m} / \mathrm{s}(6$ liter $/$ menit) & $0,221 \mathrm{~m} / \mathrm{s}$ (6 liter $/ \mathrm{menit})$ \\
\hline 3 & $0,294 \mathrm{~m} / \mathrm{s}(8$ liter $/$ menit $)$ & $0,0737 \mathrm{~m} / \mathrm{s}(2$ liter $/ \mathrm{menit})$ \\
\hline 4 & $0,294 \mathrm{~m} / \mathrm{s}(8$ liter $/$ menit $)$ & $0,147 \mathrm{~m} / \mathrm{s}(4$ liter $/ \mathrm{menit})$ \\
\hline
\end{tabular}

\subsection{Metode Diskretisasi}

Simulasi transient dibuat dengan variable time step dengan courant number dijaga di bawah 1 . Persamaan yang dipilih diselesaikan dengan metode Eulerian Multi-Fluid VoF Model. Eulerian Multi-Fluid VOF model adalah persamaan independen konservasi masa dan momentum untuk 2 fasa yang terlibat (ANSYS Theory Guide).

Simulasi unsteady memiliki konsekuensi stabilitas model sangat bergantung terhadap time-step yang ditentukan. Kriteria konvergensi yang dipakai adalah kondisi CFL (Courant-FriedrichsLewy). Korelasi perhitungan time step dan courant number berdasarkan kondisi CFL (CourantFriedrichs-Lewy) ditunjukkan pada Persamaan (1) (ANSYS Theory Guide).

$$
\Delta t \equiv \frac{C \Delta x}{U}
$$

Dengan penjelasan $\Delta \mathrm{t}$ adalah time step

$\mathrm{U}$ adalah karakteristik kecepatan dari sistem

$\Delta \mathrm{x}$ adalah jarak dari grid pada model numeris

$\mathrm{C}$ adalah bilangan Courant Number 
Konvergensi simulasi dijaga agar bilangan Courant Number tidak lebih dari 1. Selama simulasi berada di sekitar 0,6 hingga 0,9 .

\section{HASIL DAN PEMBAHASAN}

\subsection{Meshing-Grid Independent Test}

Meshing melibatkan penambahan efek dari inflation dengan growth yang seragam sebesar 1,2. Konfigurasi dibuat demikian untuk memberikan efek yang baik untuk kontak adhesi dinding (wall adhesion contact) antara minyak dan air. Penjelasan detail teknik penambahan inflation telah dijabarkan aplikasinya oleh Shi (2017). Kepadatan jumlah mesh yang yang digunakan untuk simulasi uji mesh dapat dilihat pada Gambar 2 yang menunjukkan jumlah elemen 51020, 81516, dan 141330. Meshing diubah dengan menggunakan generated/automatic mesh namun tetap mempertahankan inflation dari dinding pipa menuju ke tengah pipa. Hal ini dipilih agar secara seragam profile inflasi dapat dijaga namun memberikan kepadatan mesh yang berbeda-beda. Di mana di daerah dekat dinding, akan memiliki kepadatan lebih besar daripada tengah-tengah pipa. Hal ini diperlukan agar meningkatkan akurasi perhitungan turbulensi yang dipengaruhi oleh dinding. Konfigurasi seperti ini akan mempertahankan nilai $y^{+}$berada di sekitar 1 yang sangat akurat untuk pendekatan near wall treatment dengan near wall modelling. Di mana near wall modelling sangat cocok untuk model turbulen shear stress transport (SST) k- $\omega$ yang dipilih. Di mana shear stress transport (SST) k- $\omega$ dipilih karena mendukung nilai bilangan Reynolds dari skenario kecepatan superfisial fluida dalam simulasi. Parameter penyelesaian dalam mesh independence test ini meliputi kondisi antarmuka minyak dan air. Pada Mesh Independence Test untuk penelitian ini dilakukan simulasi dengan laju aliran yang sama pada 3 konfigurasi mesh yang berbeda. Laju aliran yang digunakan adalah 6 liter/menit minyak dan 8 liter/menit air. Diperoleh hasil mesh 81516 yang ditunjukkan pada Gambar 2 (b), memiliki kehalusan yang cukup jelas menggambarkan antarmuka dengan waktu komputasi yang cukup optimal. Perlu dicatat bahwa waktu komputasi belum termasuk waktu data postprocessing dengan CFD postprocessing dan matlab yang bisa menghabiskan waktu rata-rata 72 jam. 


\subsection{Perbandingan Visual Simulasi}
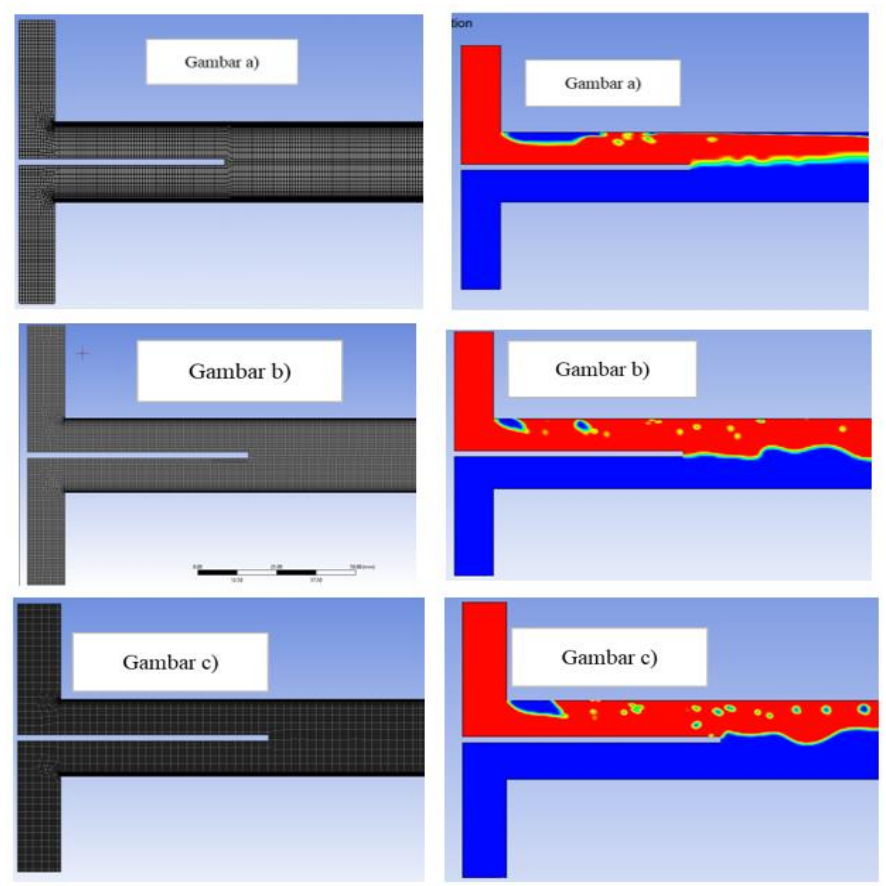

Gambar 2. Perbandingan antara konfigurasi 1 (gambar a, 51020 elemen), konfigurasi 2 jumlah (gambar b, 81516 elemen), dan konfigurasi 3 (gambar c, 141330 elemen)

Dapat disimpulkan bahwa regime aliran hasil simulasi sudah sesuai dengan regime aliran di pemetaan pola aliran Gambar 3. Maka set up input pemodelan simulasi relatif akurat untuk merepresentasikan kondisi yang diperoleh dari eksperimen.

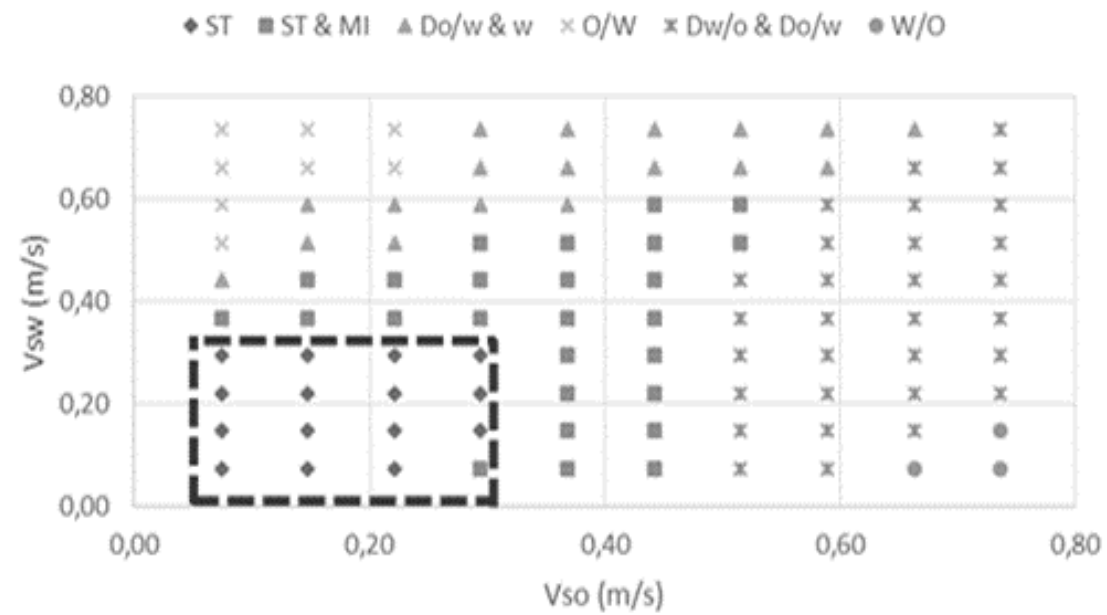

Gambar 3. Pemetaan pola aliran (Yudi, 2018) 


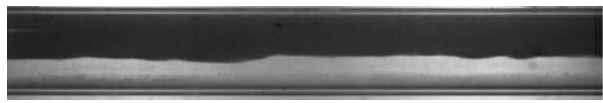

(a)

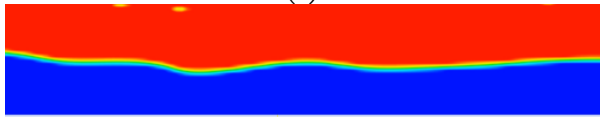

(b)

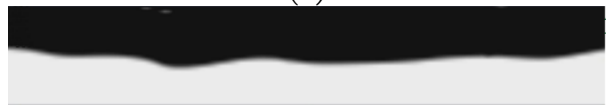

(c)

Gambar 4. Kecepatan superficial minyak 0,221 m/s dan air $0,147 \mathrm{~m} / \mathrm{s}$ di $10 \mathrm{D}$ (a) Hasil eksperimen (b) Hasil simulasi (rainbow) (c) Hasil simulasi (grayscale)

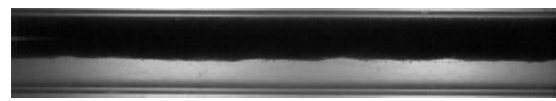

(a)

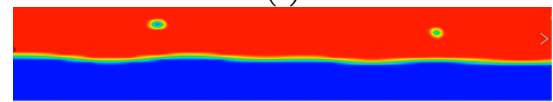

(b)

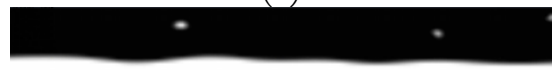

(c)

Gambar 5. Kecepatan superficial minyak $0,221 \mathrm{~m} / \mathrm{s}$ dan air $0,147 \mathrm{~m} / \mathrm{s}$ di 40D (a) Hasil eksperimen (b) Hasil simulasi (rainbow) (c) Hasil simulasi (grayscale)

Gelombang yang terbentuk ditunjukkan pada Gambar 4 memberikan kesimpulan bahwa hasil simulasi relatif cukup mewakili dengan eksperimen yang dilakukan. Simulasi berhasil membentuk tinggi dan rendah gelombang (bagian b dan c) yang relatif mirip dengan yang terbentuk di eksperimen (bagian a). Tidak hanya relatif mirip pada bagian awal pipa horizontal $10 \mathrm{D}$, hasil simulasi juga konsisten relatif mirip pada $40 \mathrm{D}$ yang ditunjukkan pada Gambar 5 . Adapun tinggi dan rendah gelombang pada $40 \mathrm{D}$ relatif lebih tenang dikarenakan letak yang lebih jauh terhadap inlet. Kondisi gelombang $40 \mathrm{D}$ tersebut menunjukkan fenomena turbulensi sudah mengalami dissipasi yang membuat gelombang relatif lebih tenang.

\subsection{Perhitungan Tebal Film dan Kecepatan Gelombang}

Untuk menghitung ketebalan film, hasil simulasi diproses menjadi video dengan menggunakan Ansys CFD Post Processing. Video kemudian akan diolah menjadi beberapa frame menggunakan MATLAB dengan metode image processing untuk mendapatkan tebal film pada aliran. Dari frame yang diperoleh dipetakan perbedaan warna antara minyak dan air, dan batas perbedaan warna dideteksi sebagai antarmuka minyak dan air. Dari perubahan antarmuka di setiap potongan frame dari video serta delay dari titik puncak gelombang yang terdeteksi terhadap referensi akan diketahui pembentukan gelombang dan dinamika kecepatan gelombang.

Dalam grafik Gambar 6, digambarkan pengaruh ketebalan film yang dipengaruhi oleh perbandingan minyak dan air, di mana jika kecepatan minyak ditingkatkan dan kecepatan air diturunkan, maka akan membentuk kecenderungan tebal film yang menurun. Dalam kondisi 
kecepatan superfisial minyak yang sama, peningkatan kecepatan superfisial air akan meningkatkan tebal film. Tebal Film yang dimaksud adalah ketebalan lapisan air pada campuran yang dihitung dari batas dinding bagian bawah permukaan pipa.

Metode yang digunakan dalam menghitung kecepatan gelombang adalah cross correlation yang dilakukan pada eksperimen oleh Bhaskara (2018). Dari hasil perhitungan cross correlation didapatkan data kecepatan gelombang untuk tiap-tiap data yang diambil. Gambar 7 menunjukkan korelasi langsung kecepatan air terhadap kecepatan gelombang sekaligus perbandingan hasil simulasi dengan hasil eksperimen dari 2 variasi kecepatan di titik 10D dan 40D. Setiap kecepatan superfisial air meningkat, maka nilai kecepatan gelombang juga mengalami peningkatan. Fenomena peningkatan nilai kecepatan gelombang ini memiliki pola yang serupa dengan fenomena yang terjadi pada aliran gas-cair.

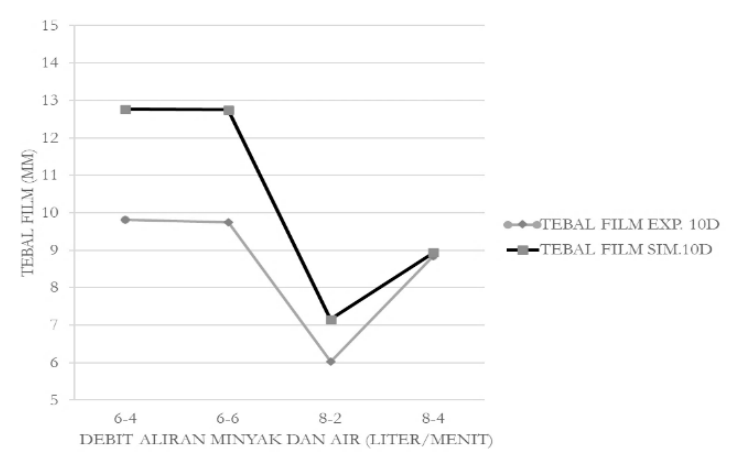

(a)

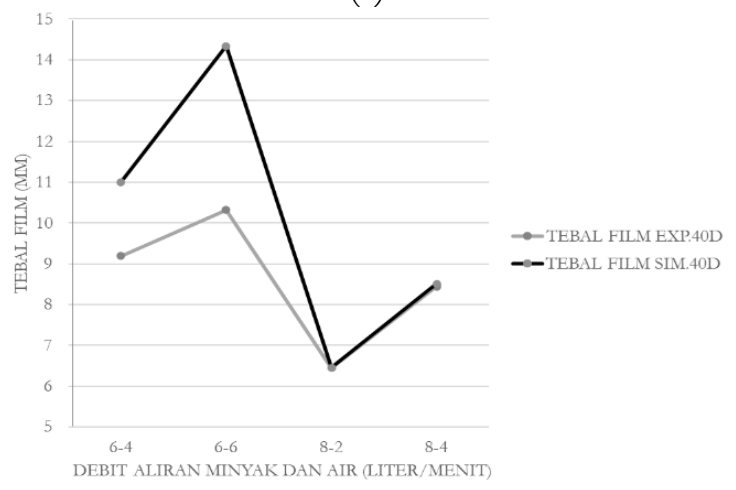

(b)

Gambar 6. Perbandingan Tebal Lapisan Film (mm) Simulasi dan Eksperimen di

(a) lokasi 10D (10x diameter)

(b) lokasi 40D (40 x diameter)

Pada penelitian yang dilakukan oleh Setyawan (2016), kecepatan gelombang mengalami peningkatan tiap ada kenaikan kecepatan superfisial fluida. Kenaikan kecepatan gelombang diperkirakan karena adanya kenaikan gaya geser pada gelombang antarmuka aliran. 


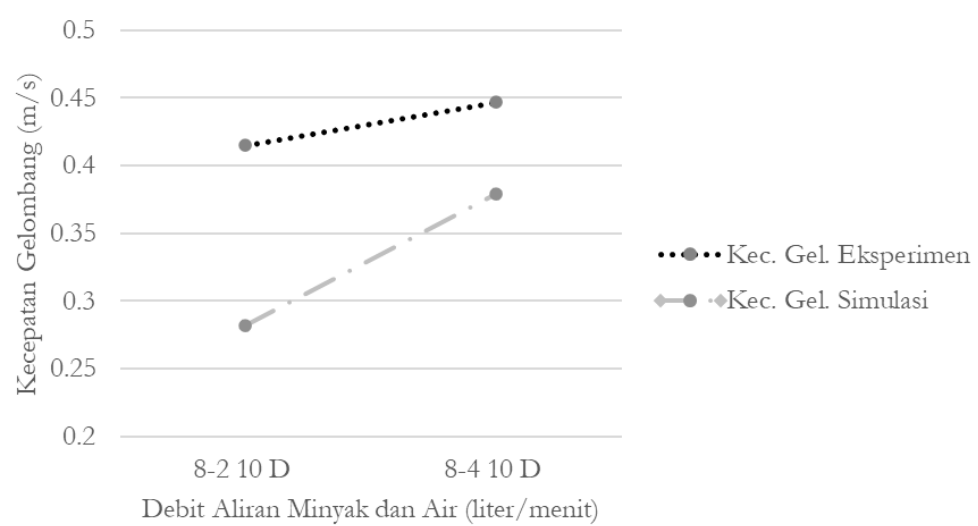

(a)

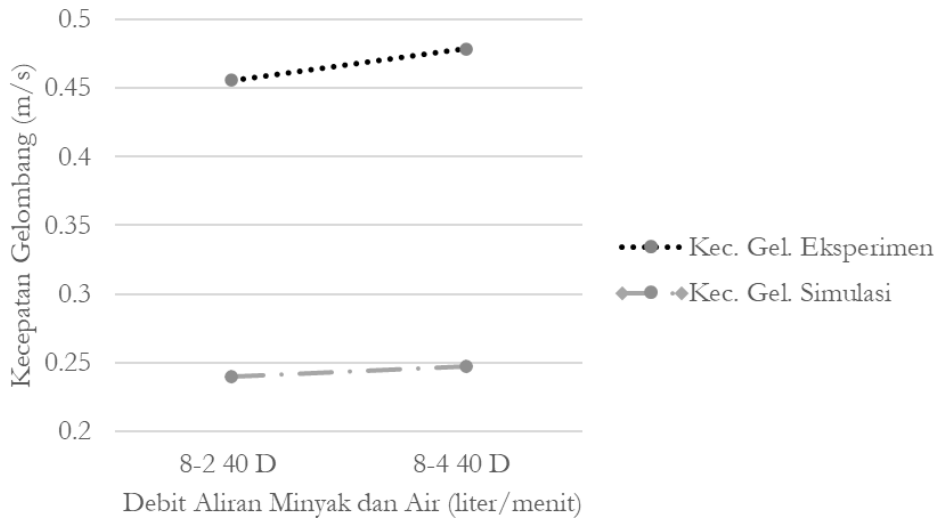

(b)

Gambar 7. Perbandingan Simulasi dan Experimen Kecepatan Gelombang (m/s) untuk kecepatan minyak 8 liter per menit pada titik (a) di 10D dan (b) di 40D

Adanya gelombang yang terbentuk pada daerah antarmuka, menunjukkan bahwa terdapat perbedaan kecepatan superfisial masing-masing fluida yang memberikan gaya geser satu sama lain pada batas antarmuka fluida yang pada akhirnya menyebabkan munculnya gelombang. Gambar 8 menunjukkan peta vektor kecepatan yang berbeda di fase minyak (merah) dan air (biru), yang dapat dijelaskan dengan teori pembentukan gelombang Kelvin-Helhmboltz Stability oleh AL-Wahaibi (2007). Dijelaskan bahwa faktor-faktor yang mempengaruhi kestabilan gelombang multifasa di antaranya adalah geometri aliran, kecepatan superfisial fluida yang menyebabkan gaya geser, sifat fisis fluida (seperti massa jenis dan viskositas), tegangan muka, serta gaya gravitasi. Terlihat dari peta vektor kecepatan pada Gambar 8 terdapat kecepatan superfisial berbeda saling berinteraksi pada antarmuka fluida. 


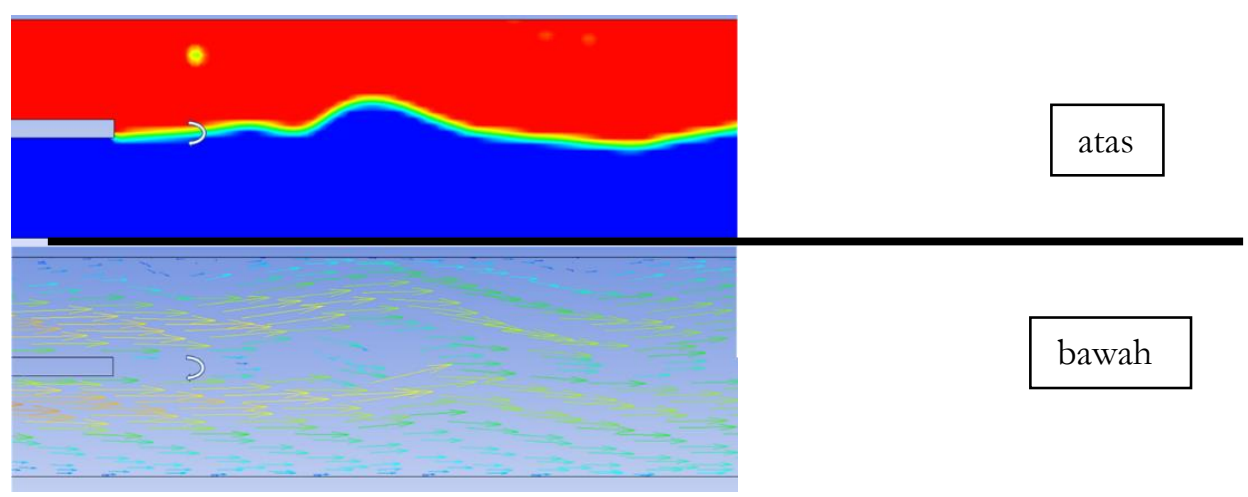

Gambar 8. Gambar gelombang antar muka (di bagian atas) di antara minyak (merah) dan air (biru) yang dilengkapi dengan Peta Vektor Kecepatan Fluida dengan tanda panah aliran (di bagian bawah)

Fenomena gaya geser akibat perbedaan kecepatan superfisial masing-masing fasa menyebabkan munculnya gelombang antarmuka konsisten di semua titik, baik pada $10 \mathrm{D}$ yang relatif dekat dengan inlet maupun pada $40 \mathrm{D}$ yang relatif jauh dari inlet. Gaya geser yang pada masing-masing fasa kemungkinan dipengaruhi oleh gaya geser hasil turbulensi pada dinding pipa dan turbulensi di inlet. Kondisi turbulensi di dinding dan inlet tersebut pada akhirnya kemungkinan saling mempengaruhi di daerah antarmuka sehingga terbentuk gelombang. Pengaruh efek turbulensi di sekitar dinding terhadap pola aliran juga dijelaskan oleh Salim (2009).

\section{KESIMPULAN}

Konfigurasi simulasi untuk mendapatkan simulasi aliran dua fasa campuran minyak dan air pada stratified flow regime dapat dicapai dengan menggunakan Model multiphase Eulerian MultiFluid VOF yang dipasangkan dengan model turbulensi shear stress transport (SST) k- $\omega$ dan turbulence damping. Jika dibandingkan dengan hasil visual eksperimen, gelombang yang terbentuk pada simulasi memiliki hasil kondisi yang saling bersesuaian. Adapun analisis fenomena dinamika kecepatan gelombang berdasarkan konfigurasi simulasi dijelaskan sebagai berikut.

a. Simulasi konsisten dengan teori terbentuknya gelombang dari Kelvin-Helmholtz Stability oleh Wahaibi (2007) [11] di mana faktor-faktor yang mempengaruhi kestabilan gelombang multifasa di antaranya salah satunya adalah perbedaan kecepatan superfisial fluida pada antarmuka yang ditunjukkan dengan peta vektor kecepatan pada simulasi.

b. Hasil simulasi untuk pengaruh kecepatan superfisial air terhadap ketebalan film dan terhadap kecepatan gelombang memiliki kecenderungan yang sama. Terdapat peningkatan ketebalan film dan kecepatan gelombang ketika kecepatan superfisial air naik pada kecepatan superfisial minyak yang sama. Kecenderungan fenomena ini sama dengan yang terjadi pada eksperimen di kedua titik pada pipa horizontal (titik $10 \mathrm{D}$ dan $40 \mathrm{D}$ dari inlet).

\section{DAFTAR PUSTAKA}

Akhlagi, M., et. Al. 2019. Multi-Fluid VoF model assessment to simulate the horizontal air-water intermittent flow. Chemical Engineering Research and Design. 152, 48-49.

Al-Wahaibi, Talal, Angeli, Panagiota, 2007, Transition Between Stratified and Non Stratified Horizontal Oil Water Flows Part I: Stability Analysis, Chemical Engineering Science, 62, 2915-2928. 
ANSYS® Fluent, Fluent Theory Guide, 2012. USA: ANSYS Inc.

Barral, A. H., Ebenezer, A., Angeli, P. 2015. Flow structure in horizontal oil - water flow. Experimental Thermal and Fluid Science, 60, 115-122.

Bhaskara, Ryan Wiratama 2018. Studi Eksperimental Perubahan Kecepatan Gelombang Aliran Minyak-Air Rezim Stratified Wavy Pada Pipa Horizontal LLCC Menggunakan Metode Image Processing. Skripsi Studi Teknik Mesin Departemen Teknik Mesin Dan Industri Fakultas Teknik Universitas Gadjah Mada.

Deendarlianto, Moeso A., Adhika W., Okto D., Khasani, Indarto., 2016. CFD Studies on the Gas-Liquid Plug Two-Phase Flow in a Horizontal Pipe. J. Petroleum Sci. and Eng. 147, 779-787.

Hanafizadeh, P., Alireza, H., Amir, K. 2015. Experimental investigation of oil-water two phase flow regime in an inclined pipe. Journal of Petroleum Science and Engineering inclined pipe, 136, 12-22

Hanif, Muhammad A. 2018. Studi Eksperimen Perubahan Frekuensi Aliran Dua Fasa Campuran Air-Minyak Tanah dengan Pola Stratified Wavy Pada Pipa Horizontal LLCC dan Pengaruhnya Terhadap Panjang Pipa Menggunakan Metode Image Processing. Skripsi Studi Teknik Mesin Departemen Teknik Mesin Dan Industri Fakultas Teknik Universitas Gadjah Mada.

Salim .M. Salim, Cheah, S.C., 2009. Wall y+ Strategy for Dealing with Wall-bounded Turbulent Flows. Proceedings of the International Multi Conference of Engineers and Computer Scientists Vol II.

Setyawan, Andriyanto, Indarto, Deendarlianto, 2016. The effect of the fluid properties on the wave velocity and wave frequency of gas-liquid annular two-phase in a horizontal pipe. Experimental Thermal and Fluid Science, 71, 25-41.

Shi, Jing., M. Gourma, Hoi Yeung. 2017. CFD Simulation of Horizontal oil-water flow with matched density and medium viscosity ratio in different flow regimes. J. Petroleum Sci. and Eng. 151, 373-383.

Yudi, Olga Priandana. 2018. Studi Eksperimental Pemetaan Pola Aliran Minyak-Air Pada Pipa Horizontal Separator Liquid-Liquid Cylindrical Cyclone. Fluid Mechanics Research UGM. 